\title{
PERBEDAAN PELAYANAN IGD BERDASARKAN TRIASE DI RUMAH SAKIT PETROKIMIA GRESIK SEBELUM DAN SESUDAH ADANYA ASURANSI BPJS KESEHATAN
}

\author{
The Differences Of IGD Serving Based On Triase In RS Petrokimia Gresik Before \\ And After Teatment by BPJS Insurance \\ Efa Mudalifah $^{1}$, Diah Ratnasari ${ }^{2}$ \\ Fakultas Kesehatan Universitas Muhammadiyah Gresik, Jl. Proklamasi 54 Gresik \\ Fakultas Kesehatan Universitas Muhammadiyah Gresik, Jl. Proklamasi 54 Gresik \\ Email:mudalifahefa@gmail.com \\ diahratnasari@umg.ac.id
}

\begin{abstract}
Every hospital has emergency room (IGD) facility for 24 hours. The duty for this section is to give patirnt service with fast respond for emergency health case. In other hand, BPJS give an impact such as differences service in IGD Petrokimia Gresik Hospital. The purpose of this research is to know the different of disease based on triase and to get differences between pharmaceutical supplies in IGD Petrokimia Gresik after getting BPJS insurance. The method of this research is qualitative descriptive. Primer data is used as instrument research such as interview and direct observation. Meanwhile secondary data of this research is IDG documents. The result of this research showed that there was a differences between case or disease that happened in IGD Petrokimia Gresik,not only emergency case that handled in IGD after get BPJS insurance. The second result showed a differences between pharmaceutical supplies after BPJS insurance treatment. Patent medicine had changed to Generic medicine.
\end{abstract}

Key word : BPJS Kesehatan, depo farmasi, IGD

\section{PENDAHULUAN}

Rumah sakit adalah suatu lembaga komunitas yang berperan sebagai jasa penyembuhan penderita dan pemulihan kesehatan pasien. Pelayanan profesional dan handal diperlukan untuk menjadi pilihan utama masyarakat. Hal itu juga perlu ditunjang dengan adanya layanan emergency 24 jam yang wajib dimiliki setiap rumah sakit.Untuk menunjang pelayanan tersebut, setiap rumah sakit memiliki fasilitas IGD.

IGD adalah suatu unit yang sangat penting dan tidak dapat dipisahkan dalam suatu rumah sakit. Fungsinya adalah untuk menerima, menstabilkan dan mengatur pasien yang menunjukkan gejala yang bervariasi dan gawat, serta juga kondisi-kondisi yang sifatnya tidak gawat. Di IGD, sistem triase gawat darurat medis digunakan untuk menentukan pasien mana yang harus ditangani lebih dahulu dibandingkan dengan pasien lainnya. Konsep awal triase gawat darurat adalah membagi pasien menjadi 3 kategori, yaitu urgent, immediate, dan non-urgent. Kategori pasien urgent digolongkan dalam triase merah, kategori pasien immediate digolongkan dalam triase kuning, dan kategori pasien non-urgent digolongkan dalam triase hijau. Konsep yang pertama kali diciptakan untuk situasi perang ini masih berlaku untuk digunakan di zaman modern ini, dan digunakan di berbagai negara, seperti, Inggris, Belanda, Swedia, India, Australia, dan organisasi militer NATO (Pusponegoro, 2010).

Dalam kondisi saat ini, dengan adanya BPJS kesehatan hampir semua rumah sakit terutama di IGD Rumah Sakit Petrokimia Gresik mengalami kenaikan jumlah pengunjung(pasien). Pasien yang datang ke IGD tidak hanya pasien dengan keadaan gawat darurat saja, melainkan banyak dari mereka yang datang dengan diagnosa ringan sampai sedang. Hal ini disebabkan karena banyak dari mereka yang kurang memahami peraturan perundang-undangan BPJS kesehatan. Pasien BPJS kesehatan dengan diagnosa tidak gawat darurat seharusnya tidak bisa dilayani di IGD dan harus memeriksakan diri terlebih dahulu ke faskes tingkat 1 yaitu klinik PPK atau puskesmas. 
Berdasarkan uraian diatas, maka peneliti melakukan penelitian dengan judul "Perbedaan Pelayanan IGD Rumah Sakit Petrokimia Gresik Sebelum dan Sesudah Adanya Asuransi BPJS Kesehatan"

\section{II.TINJAUAN PUSTAKA}

\subsection{Instalasi Gawat Darurat}

Instalasi Gawat Darurat (IGD) adalah instalasi pelayanan rumah sakit yang memberikan pelayanan pertama selama 24 jam pada pasien dengan ancaman kematian dan kecacatan secara terpadu dengan melibatkan multidisiplin ilmu. IGD merupakan suatu unit integral dalam satu rumah sakit, dimana semua pengalaman pasien yang pernah datang ke IGD tersebut akan dapat menjadi pengaruh yang besar bagi masyarakat tentang bagaimana gambaran rumah sakit itu sebenarnya (DepKes RI, 2004).

Fungsi IGD adalah untuk menerima, menstabilkan dan mengatur pasien yang menunjukkan gejala yang bervariasi dan gawat, serta juga kondisi-kondisi yang sifatnya tidak gawat. IGD juga menyediakan sarana penerimaan untuk penatalaksanaan pasien dalam keadaan bencana. Hal ini merupakan bagian dari perannya didalam membantu keadaan bencana yang terjadi di tiap daerah (DepKes RI, 2004).

\subsection{Triase}

Triase adalah suatu sistem pembagian prioritas pasien berdasarkan berat ringannya kondisi pasien atau kegawatanya yang memerlukan tindakan segera. Dalam triase, perawat dan dokter mempunyai batasan waktu (response time) untuk mengkaji keadaan dan memberikan tindakan secepatnya yaitu $<10$ menit (Pusponegoro, 2010). Triase yang akurat merupakan kunci untuk tindakan yang efisien di instalasi gawat darurat (Manitoba Health, 2010). Penatalaksanaan pada kondisi darurat didasarkan pada respon klinis daripada urutan kedatangan (ACEM, 2005).

Penggolongan pasien dengan sistem triase medis yaitu memilah-milih pasien berdasarkan kondisi pasien saat masuk ruang perawatan dan memberikan kode warna untuk pasien, mulai dari merah, kuning, hijau, putih dan hitam. Arti dari warna-warna tersebut yaitu:

\section{Merah}

Kode warna merah diberikan kepada pasien yang jika tidak diberikan penanganan dengan cepat, maka pasien pasti akan meninggal, dengan syarat pasien tersebut masih memiliki kemungkinan untuk dapat hidup. Contohnya seperti pasien dengan gangguan pernapasan, trauma kepala dengan ukuran pupil mata yang tidak sama, dan perdarahan hebat.

\section{Kuning}

Kode warna kuning diberikan kepada pasien yang memerlukan perawatan segera, tetapi masih dapat ditunda karena ia masih dalam kondisi stabil. Pasien dengan kode kuning masih memerlukan perawatan di rumah sakit dan pada kondisi normal akan segera ditangani. Contohnya seperti pasien dengan patah tulang di beberapa tempat, patah tulang paha atau panggul, luka bakar luas, dan trauma kepala.

\section{Hijau}

Kode warna hijau diberikan kepada mereka yang memerlukan perawatan tetapi masih dapat ditunda. Biasanya pasien cedera yang masih sadar dan bisa berjalan masuk dalam kategori ini. Ketika pasien lain yang dalam keadaan gawat sudah selesai ditangani, maka pasien dengan kodewarna hijau akan ditangani. Contohnya seperti pasien dengan patah tulang ringan, luka bakar minimal, atau luka ringan.

4. Putih

Kode warna putih diberikan kepada pasien hanya dengan cidera minimal, di mana tidak diperlukan penanganan dokter.

5. Hitam:

Kode warna hitam diberikan kepada pasien yang setelah diperiksa tidak menunjukkan tandatanda kehidupan. Misalnya, mereka yang masih hidup tetapi mengalami cidera yang amat parah, sehingga meskipun segera ditangani, pasien tetap akan meninggal.

\subsection{BPJS}

Menurut UU Peraturan BPJS Kesehatan No. 1 Tahun 2014 Tentang Penyelenggaraan 
Jaminan Kesehatan, Jaminan kesehatan adalah jaminan berupa perlindungan kesehatan agar peserta memperoleh manfaat pemeliharaan kesehatan dan perlindungan dalam memenuhi kebutuhan dasar kesehatan yang diberikan kepada setiap orang yang telah membayar iuran atau iurannya dibayar oleh pemerintah. Biaya yang harus dibayarkan oleh peserta BPJS kesehatan perbulan yaitu sesuai dengan tingkat kelas yang diambil oleh masing-masing peserta.

Penyelenggara Pelayanan Kesehatan Menurut Peraturan BPJS Kesehatan No. 1 Tahun 2014 Tentang Penyelenggaraan Jaminan Kesehatan (Pelayanan Kesehatan Pada Fasilitas Kesehatan Tingkat Pertama) fasilitas kesehatan tingkat pertama terdiri dari: puskesmas atau yang setara; praktik dokter; praktik dokter gigi; klinik pratama atau yang setara termasuk fasilitas kesehatan tingkat pertama milik TNI/POLRI; dan rumah sakit kelas $\mathrm{D}$ pratama atau yang setara.

Pelayanan kesehatan pada fasilitas kesehatan tingkat pertama terdiri atas:

1) Pelayanan kesehatan rawat jalan tingkat pertama;

2) Pelayanan kesehatan rawat inap tingkat pertama;

3) Pelayanan kesehatan gigi;

4) Pelayanan kesehatan oleh bidan dan perawat.

BPJS Kesehatan berusaha memberikan pelayanan terbaik kepada peserta untuk bisa mendapatkan jaminan kesehatan. Untuk bisa mendapatkan jaminan kesehatan dari BPJS, peserta diharapkan mengikuti aturan dan prosedur yang telah dibuat, yaitu berobat dengan sistem rujukan, dimana ketika peserta sakit maka diharapkan berobat ke faskes 1 terlebih dahulu, kecuali jika peserta sakit dalam keadaan darurat yang membutuhkan pertolongan secepatnya. (BPJS Kesehatan,2018).

\section{III.METODE PENELITIAN}

Penelitian ini dilaksanakan mulai bulan April 2018 sampai dengan bulan Juli 2018. Penelitian ini dilaksanakan di Instalasi Gawat Darurat (IGD) Rumah Sakit Petrokimia Gresik.
Objek pengamatan dalam penelitian ini yaitu (1) Perbedaan jenis penyakit/kasus yang dilayani di IGD Rumah Sakit Petrokimia Gresik sebelum dan sesudah adanya asuransi BPJS kesehatan. (2) Perbedaan perbekalan farmasi di depo farmasi IGD Rumah Sakit Petrokimia Gresik sebelum dan sesudah adanya asuransi BPJS kesehatan.

Prosedur pengamatan yang dilakukan yaitu :

1. Langkah awal, peneliti melakukan observasi awal ke unit-unit Rumah Sakit Petrokimia Gresik untuk mengidentifikasi masalah yang ada di beberapa unit di Rumah Sakit Petrokimia Gresik dan merumuskan masalah.

2. Menetapkan IGD Rumah Sakit Petrokimia Gresik sebagai tempat penelitian.

3. Menentukan metode penelitian apa yang akan digunakan.

4. Mengumpulkan data sekunder yang diperlukan untuk penelitian. Data sekunder yang diambil adalah data pada tahun 2012 - 2017 (sebelum adanya BPJS kesehatan dan sesudah adanya BPJS kesehatan).

5. Membuat pedoman wawancara.

6. Melakukan wawancara internal kepada penanggung jawab IGD dan apoteker penanggung jawab depo farmasi IGD dengan menggunakan pedoman wawancara dan perekam suara.

7. Mengolah dan menganalisis data

Teknik pengumpulan data yang digunakan dalam sumber data primer yaitu survey lapangan dengan interview internal kepada apoteker depo farmasi IGD dan penanggung jawab IGD. Alat yang digunakan untuk pengumpulan data primer yaitu pedoman wawancara, dan observasi langsung. Data sekunder berupa dokumen jumlah kunjungan pasien perhari yang telah digolongkan sesuai dengan sistem triase, jenis obat yang tersedia di depo farmasi IGD sebelum dan sesudah adanya asuransi BPJS kesehatan. Teknik analisis data yang digunakan adalah analisis kualitatif yang bersifat deskriptif.

\section{HASIL DAN PEMBAHASAN}

Adanya BPJS Kesehatan berdampak pada perbedaan kasus/penyakit yang ditangani di IGD Rumah Sakit Petrokimia Gresik yang disajikan pada Tabel 1. 
Tabel 1 Perbedaan jenis penyakit/kasus sebelum dan sesudah adanya BPJS kesehatan

\begin{tabular}{|c|c|c|c|}
\hline \multicolumn{4}{|c|}{$\begin{array}{l}\text { Penyakit atau Kasus yang Ditangani di IGD Rumah Sakit } \\
\text { Petrokimia Gresik }\end{array}$} \\
\hline \multicolumn{2}{|c|}{ Sebelum BPJS Kesehatan } & \multicolumn{2}{|c|}{ Sesudah BPJS Kesehatan } \\
\hline 1. & Stroke Perdarahan & 1. & Stroke Perdarahan \\
\hline 2. & $\begin{array}{lr}\text { Sindroma } & \text { Coroner } \\
\text { Acut } & \text { (serangan } \\
\text { jantung } & \text { coroner } \\
\text { mendadak) } & \\
\end{array}$ & 2. & $\begin{array}{lr}\text { Sindroma } & \text { Coroner } \\
\text { Acut } & \text { (serangan } \\
\text { jantung } & \text { coroner } \\
\text { mendadak) } & \\
\end{array}$ \\
\hline 3. & Cidera Otak Berat & 3. & Cidera Otak Berat \\
\hline 4. & $\begin{array}{l}\text { Open Fractur (patah } \\
\text { tulang terbuka) }\end{array}$ & 4. & $\begin{array}{l}\text { Open Fractur(patah } \\
\text { tulang terbuka) }\end{array}$ \\
\hline \multirow[t]{9}{*}{5.} & \multirow[t]{9}{*}{ Kejang Demam } & 5. & Kejang Demam \\
\hline & & 6. & $\begin{array}{l}\text { DHF (Dengue } \\
\text { Hemorrhagic Fever) }\end{array}$ \\
\hline & & 7. & $\begin{array}{l}\text { LBP (Low Back Point) } \\
\text { nyeri punggung bawah }\end{array}$ \\
\hline & & 8 & Dypepsia (Lambung) \\
\hline & & 9. & Asma \\
\hline & & 10 & Diare \\
\hline & & 11. & Mual Muntah \\
\hline & & 12. & Vertigo \\
\hline & & 13. & Radang tenggorokan \\
\hline
\end{tabular}

Tabel 1 menjelaskan bahwa sebelum adanya asuransi BPJS kesehatan, IGD Rumah Sakit Petrokimia Gresik melayani beberapa kasus/penyakit kegawatdaruratan saja yaitu stroke perdarahan, sindroma coroner acut (serangan jantung coroner mendadak), cidera otak berat, open fractur (patah tulang terbuka), kejang demam. Namun,setelah adanya asuransi BPJS kesehatan, IGD Rumah Sakit Petrokimia Gresik melayani banyak kasus yaitu stroke perdarahan, sindroma coroner acut (serangan jantung coroner mendadak), cidera otak berat, open fractur (patah tulang terbuka), kejang demam, DHF (dengue hemorrhagic fever), LBP (Low Back Point) nyeri punggung bawah, Dypepsia (lambung), asma, diare, mual muntah, vertigo, batuk pilek radang tenggorokan. Diantara kasus-kasus tersebut ada beberapa yang tidak masuk dalam kategori kegawatdaruratan (masih bisa ditunda penanganannya) yaitu dypepsia (lambung), diare 12 kali dalam sehari, mual muntah 1-2 kali dalam sehari, batuk pilek radang tenggorokan.

Banyaknya kasus/penyakit yang dilayani di IGD sesudah adanya asuransi BPJS kesehatan menyebabkan diberlakukanya sistem penggolongan pasien berdasarkan tingkat kegawatdaruratannya (sistem triase). Di bawah ini merupakan hasil penggolongan pasien dengan sistem triase di IGD Rumah Sakit Petrokimia Gresik. Penggolongan sistem triase di mulai tahun 2015-2017.

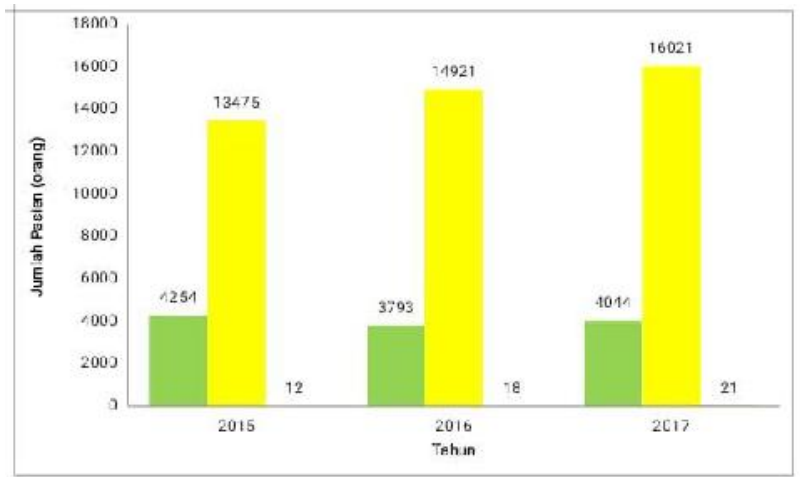

Gambar 1. Penggolongan sistem triase IGD Rumah Sakit Petrokimia Gresik

Gambar 1 menjelaskan bahwa penggolongan pasien dengan sistem triase di IGD Rumah Sakit Petrokimia Gresik diberlakukan pada akhir tahun 2014. Hal ini disebabkan karena semakin bertambahnya tingkat kunjungan pasien dan semakin banyaknya diagnosa yang tidak masuk dalam kategori kegawatdaruratan. Pada awal tahun 2015 sampai dengan 2017 pasien yang berobat di IGD mayoritas menggunakan asuransi BPJS kesehatan. Berdasarkan kondisinya, pasien-pasien tersebut dibagi menjadi tiga golongan, yaitu triase hijau, kuning, dan merah.

Kasus/ penyakit yang dikategorikan triase hijau merupakan kasus/penyakit yang tingkat kegawatdaruratanya ringan. Jenis penyakit yang tergolong dalam triase hijau yaitu pusing, batuk pilek radang tenggorokan, mual/muntah 1-2 kali dalam sehari, diare 1-2 kali dalam sehari, demam 12 hari dengan suhu tubuh 37oC. Jumlah kasus/penyakit dengan triase hijau dari tahun 20152017 relatif tidak mengalami perubahan yang signifikan, tahun 2015 jumlahnya 4.254 pasien, tahun 2016 jumlahnya 3.793 pasien, dan tahun 2017 jumlahnya 4.044 pasien.

Kasus/ penyakit yang dikategorikan triase kuning merupakan kasus/penyakit yang tingkat kegawatdaruratanya sedang. Jenis penyakit yang tergolong triase kuning yaitu dypepsia (lambung), vertigo, diare 10 kali dalam sehari, Dengue Hemorraghic Fever (DHF), Low Back Point (LBP) nyeri punggung bawah. Jumlah kasus/penyakit 
dengan triase kuning dari tahun 2015-2017 relatif tidak mengalami perubahan yang signifikan, tahun 2015 jumlahnya 13.475pasien, tahun 2016 jumlahnya 14.921 pasien, tahun 2017 jumlahnya 16.021 pasien.

Kasus/ penyakit yang dikategorikan triase merah merupakan kasus/penyakit yang tingkat kegawatdaruratanya berat. Jenis penyakit yang tergolong triase merah yaitu stroke perdarahan, sidroma coroner acut (serangan jantung mendadak), cidera otak berat, open fractur (patah tulang terbuka, kejang demam. Jumlah kasus/penyakit dengan triase merah dari tahun 2015-2017 tidak mengalami perubahan yang signifikan, tahun 2015 jumlahnya 12 pasien, tahun 2016 jumlahnya 18 pasien, tahun 2017 jumlahnya 21 pasien.

Adanya BPJS Kesehatan juga berdampak pada perubahan persediaan farmasi yang ditangani di IGD Rumah Sakit Petrokimia Gresik yang disajikan pada Tabel 2.

Tabel 2. Perbedaan Perbekalan Farmasi Sebelum dan Sesudah adanya BPJS Kesehatan

\begin{tabular}{|c|c|c|c|}
\hline \multicolumn{4}{|c|}{ Perbekalan Farmasi di IGD Rumah Sakit Petrokimia Gresik } \\
\hline \multicolumn{2}{|c|}{ Sebelum BPJS Kesehatan } & \multicolumn{2}{|c|}{ Sesudah BPJS Kesehatan } \\
\hline \multirow[t]{2}{*}{1} & Stroke Perdarahan & 1. & Stroke Perdarahan \\
\hline & $\begin{array}{ll}\text { Plasminek } & \text { Injeksi, } \\
\text { Neurotam } & \text { Injeksi, } \\
\text { Antrain } & \text { Injeksi, } \\
\text { Cholinaar } & \text { Injeksi, } \\
\text { Acran Injeksi, Invomit } \\
\text { Injeksi, Perdipine } \\
\text { Injeksi,Manitol Infus, } \\
\text { selang O2masker. }\end{array}$ & & $\begin{array}{lr}\text { Asam } & \text { Tranexsamat } \\
\text { Injeksi, } & \text { Piracetam } \\
\text { Injeksi, } & \text { Santagesik } \\
\text { Injeksi, } & \text { Citicoline } \\
\text { Injeksi, } & \text { Ranitidine } \\
\text { Injeksi, } & \text { Ondansetron } \\
\text { Injeksi, } & \text { Nicardipine } \\
\text { Injeksi, } & \text { Manitol } \\
\text { Infus, } & \text { Selang } \\
\text { O2masker } & \end{array}$ \\
\hline \multirow[t]{2}{*}{2} & $\begin{array}{l}\text { Sindroma Coroner } \\
\text { Acut (serangan jantung } \\
\text { coroner mendadak) }\end{array}$ & \multirow[t]{2}{*}{2.} & $\begin{array}{lr}\text { Sindroma } & \text { Coroner } \\
\text { Acut } & \text { (serangan } \\
\text { jantung } & \text { coroner } \\
\text { mendadak) } & \\
\end{array}$ \\
\hline & $\begin{array}{lr}\text { Terodel } & \text { Tablet,Cardio } \\
\text { Aspirin } & \text { Tablet, } \\
\text { Cedocard } & \text { Tablet, } \\
\text { Selang } & O 2 \\
\text { Masker,Ringer } & \text { Lactat, } \\
\text { Cedocard } & \text { Injeksi, } \\
\text { Tensivask Tablet. }\end{array}$ & & $\begin{array}{lr}\text { Clopidogrel } & \text { Tablet, } \\
\text { Asetosal } & \text { Tablet, } \\
\text { ISDN Tablet, } & \text { Selang } \\
\text { O2masker, } & \text { Ringer } \\
\text { Lactat(Jkn), ISDN } \\
\text { Injeksi, Amlodipin } \\
\text { Tablet. }\end{array}$ \\
\hline \multirow[t]{2}{*}{3} & Cidera Otak Berat & \multirow[t]{2}{*}{3.} & Cidera Otak Berat \\
\hline & $\begin{array}{lr}\text { Invomit } & \text { Injeksi, Acran } \\
\text { Injeksi, } & \text { Neurotam } \\
\text { Injeksi, } & \text { Cholinaar } \\
\text { Injeksi, } & \text { Antrain Injeksi, }\end{array}$ & & 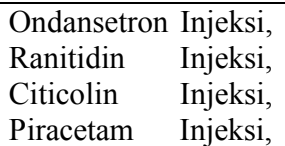 \\
\hline
\end{tabular}

\begin{tabular}{|c|c|c|c|}
\hline & $\begin{array}{l}\text { Mayo, } \quad \text { Manitol, } \\
\text { Electrode, Cervical } \\
\text { Collar, Selang Non } \\
\text { Rebriting, Nacl 0,9\% }\end{array}$ & & $\begin{array}{lr}\text { Santagesik } & \text { Injeksi, } \\
\text { Mayo,Manitol (Jkn), } \\
\mathrm{NaCl} & 0,9 \%(\mathrm{Jkn}), \\
\text { Selang } & \text { Non } \\
\text { Rebriting, } & \text { Cervical } \\
\text { Collar. } & \\
\end{array}$ \\
\hline \multirow[t]{2}{*}{4} & $\begin{array}{l}\text { Open Fractur (patah } \\
\text { tulang terbuka) }\end{array}$ & \multirow[t]{2}{*}{4.} & $\begin{array}{l}\text { Open Fractur(patah } \\
\text { tulang terbuka) }\end{array}$ \\
\hline & $\begin{array}{lr}\text { Tetagam } & \text { Injeksi, } \\
\text { Hecting Set } & \text { Situation, } \\
\text { Remopain } & \text { Injeksi, } \\
\text { Spalk, } & \text { Elastis } \\
\text { Bandage } & \end{array}$ & & $\begin{array}{l}\text { ATS Injeksi, } \\
\text { Hecting set situation } \\
(\mathrm{JKN}), \quad \text { Ketoroloc } \\
\text { Injeksi, } \quad \text { Spalk, } \\
\text { Elastis Bandage }\end{array}$ \\
\hline \multirow[t]{2}{*}{5} & Kejang Demam & \multirow[t]{2}{*}{5.} & Kejang Demam \\
\hline & 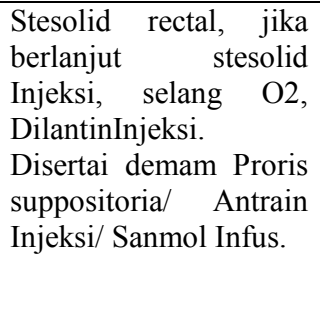 & & $\begin{array}{lr}\begin{array}{l}\text { Diazepam } \\
\text { jika rectal, } \\
\text { Diazepam }\end{array} \text { Injeksianjut } \\
\text { selang O2, Phenitoin } \\
\text { Injeksi. Disertai } \\
\text { demam Ibuprofen } \\
\text { suppositoria/ } \\
\text { Santagesik Injeksi / } \\
\text { Paracetamol Infus. }\end{array}$ \\
\hline & & \multirow[t]{2}{*}{6.} & $\begin{array}{l}\text { DHF (Dengue } \\
\text { Hemorrhagic Fever) }\end{array}$ \\
\hline & & & $\begin{array}{l}\text { Infus RL, Santagesik } \\
\text { Injeksi, Ranitidin } \\
\text { Injeksi, Omeprazole } \\
\text { Injeksi, Ondansetron } \\
\text { Injeksi }\end{array}$ \\
\hline & & \multirow[t]{2}{*}{7.} & $\begin{array}{l}\text { LBP (Low Back } \\
\text { Point) nyeri punggung } \\
\text { bawah }\end{array}$ \\
\hline & & & $\begin{array}{l}\text { Ketorolac Injeksi, } \\
\text { Analsik/Esperison } \\
\text { Tablet. }\end{array}$ \\
\hline & & \multirow[t]{2}{*}{8} & Dypepsia (Lambung) \\
\hline & & & $\begin{array}{l}\text { Ranitidin Injeksi, } \\
\text { Omeprazole Injeksi, } \\
\text { Domperidon Tablet, } \\
\text { Lansoprazole Tablet. }\end{array}$ \\
\hline & & \multirow[t]{2}{*}{9.} & Asma \\
\hline & & & $\begin{array}{l}\text { Ventolin nebul, } \\
\text { Pulmicort nebul, } \\
\text { racikan obat batuk } \\
\text { sesak (Ambroxol } \\
\text { Tablet, Salbutamol } \\
\text { Tablet, Tremenza } \\
\text { Tablet, Cortidek } \\
\text { Tablet). }\end{array}$ \\
\hline & & \multirow[t]{2}{*}{10.} & Diare \\
\hline & & & $\begin{array}{lr}\text { Infusan } & \text { RL, Diagit } \\
\text { Tablet, Loperamid } \\
\text { Tablet, Oralit, } \\
\text { Santagesik Injeksi }\end{array}$ \\
\hline & & \multirow[t]{2}{*}{11.} & Mual Muntah \\
\hline & & & $\begin{array}{l}\text { Ondansetron Injeksi, } \\
\text { Pantoprazole Injeksi, } \\
\text { Ranitidine Injeksi, } \\
\text { Domperidone } \\
\text { Tablet. }\end{array}$ \\
\hline & & \multirow[t]{2}{*}{12.} & Vertigo \\
\hline & & & Santagesik Injeksi, \\
\hline
\end{tabular}




\begin{tabular}{|l|l|l|} 
& & $\begin{array}{l}\text { Ondansetron Injeksi, } \\
\text { Pantoprazole Injeksi, } \\
\text { Betahistine mesilate } \\
\text { Tablet. Ondansetron } \\
\text { Tablet }\end{array}$ \\
\hline 13. & $\begin{array}{l}\text { Radang tenggorokan } \\
\text { Racikan batuk pilek } \\
\text { radang. }\end{array}$ \\
\hline
\end{tabular}

Tabel 2 menjelaskan bahwa jenis-jenis obat di depo farmasi IGD Rumah Sakit Petrokimia Gresik sebelum adanya BPJS kesehatan mayoritas menggunakan obat paten yang relatif mahal. Contoh nya Antrain Injeksi, Invomit Injeksi, Pumpitor Injeksi, Plasminek Injeksi, Neurotam Injeksi. Setelah di berlakukannya asuransi BPJS kesehatan oleh pemerintah yang menyebabkan peningkatan jumlah pasien di IGD, maka terjadi pergantian sebagian isi formularium obat di depo farmasi IGD Rumah Sakit Petrokimia Gresik yang disesuaikan dengan jumlah plafon dari BPJS kesehatan. Harga obat-obatan yang ada di formularium tersebut relatif lebih murah karena mayoritas obat generik. Contoh obat-obat BPJS kesehatan yaitu Pantoprazole Injeksi, Betahistin mesilate Tablet, Ondansetron Tablet, Santagesik Injeksi, Ranitidin Injeksi, Omeprazole Injeksi, Ondansetron Injeksi, Asam Tranexsamat Injeksi, Piracetam Injeksi, Santagesik Injeksi, Citicoline Injeksi, Ranitidine Injeksi, Ondansetron Injeksi, Nicardipine Injeksi, Clopidogrel Tablet, Asetosal Tablet, ISDN Tablet.

\section{PENUTUP}

Kesimpulan yang dapat diambil dari penelitian ini yaitu:

(1) Terdapat perbedaan kasus/penyakit yang dilayani di IGD Rumah Sakit Petrokimia Gresik,sesudah adanya BPJS kesehatan pasien yang dilayani di IGD tidak kasus kegawatdaruratan saja.

(2) Terdapat perbedaan perbekalan farmasi di depo farmasi IGD sesudah adanya asuransi BPJS kesehatan yaitu dari penggunaan obat paten beralih ke obat generik. Jumlah obat mengalami peningkatan yang signifikan yaitu 184 item (tahun 2016) menjadi 296 item (tahun 2017).
Saran:

Perlunya penyuluhan tentang peraturanperaturan BPJS kesehatan, agar seluruh pengguna BPJS kesehatan paham dengan aturan berobat. Khususnya pasien yang akan berobat di IGD sehingga dapat tercapainya ketertiban dalam mencapai kesehatan.

\section{DAFTAR PUSTAKA}

[1] BPJS Kesehatan. 2018.Peraturan Berobat di Faskes Tingkat I, ( https://www.bpjskesehatan.go.id/bpjs/) diakses tanggal 18 Mei 2018.

[2] Departemen Kesehatan RI. 2009. Standar Instalasi Gawat Darurat(IGD) Rumah Sakit. Jakarta: Departemen Kesehatan RI. [3] Departemen Kesehatan RI. 2006. Fungsi dan Tugas IGD. Jakarta: Departemen Kesehatan RI. .

[4] Manajemen RS. 2015. Formularium Rumah Sakit.

[5] MenKes RI. 2004.Keputusan Menteri Kesehatan Republik Indonesia No. 1197/MENKES/SK/X/2004 tentang Fungsi Pelayanan Farmasi Rumah Sakit Sebagai Pengelola Perbekalan Farmasi. 2004. Jakarta: Menteri Kesehatan Republik Indonesia.

[6] MenKes RI. 2008.Keputusan Menteri Kesehatan Republik Indonesia No. 1121/MENKES/SK/XII/2008 tentang Pedoman Teknis Pengadaan Obat Publik Dan Perbekalan Kesehatan Untuk Pelayanan Kesehatan Dasar. 2008. Jakarta: Menteri Kesehatan Republik Indonesia.

[7] MenKes RI. 2014.Keputusan Menteri Kesehatan Republik Indonesia No.1197/MENKES/SK/X/2004 tentang Standar Pelayanan Farmasi di Rumah Sakit.2004. Jakarta: Menteri Kesehatan Republik Indonesia.

[8] Quyumi, E. 2013. Pengalaman Pasien Prioritas Paling Rendah pada Klasifikasi Triage di IGD RSUD dr. Iskak Tulungagung, Jurnal Ilmu Kesehatan, Vol.2, No.1.

[9] Undang-undang Republik Indonesia Pasal 5 Nomor 44 Tahun 2009 tentang Tugas dan Fungsi Rumah Sakit: 2009. Jakarta. 